\title{
Research on the Development of Language Industry in Yunnan Province from the Perspective of Language Economics
}

\author{
Lisha Ma \\ Yunnan College of Business Management, Yunnan, Kunming, 650106
}

Keywords: Development, Language Industry, Yunnan Province, Language Economics

\begin{abstract}
Linguistic economics is an emerging fringe discipline across disciplines such as pedagogy, linguistics, and economics. In recent years, scholars at home and abroad have begun to pay attention to the study of foreign language talent training from the perspective of language economics. By reviewing the study of language education from the perspective of language economics at home and abroad, it is a new perspective to analyze the cultivation of foreign language talents in the new economic environment of minority areas in China. It is a foreign language education for minority areas. It provides a new perspective and analytical framework, and also promotes foreign language teaching and research in minority areas.
\end{abstract}

\section{Introduction}

The development of foreign language education is based on social and economic development. The level of social and economic development provides economic conditions and material and technical conditions for the development of foreign language education. At the same time, it also puts forward certain objective needs and promotes its development. Foreign language education needs to conform to social and economic development and improve with its corresponding development. According to the basic theory of linguistic economics: the number of individuals and institutions using a particular language (ie, the density of the language used) in a particular region is the primary factor determining the economic utility of the language [1]. We must make timely adjustments to language education policies and plans based on socioeconomic development and based on the theory of language economic value and the cost-benefit theory of education. Therefore, what foreign language talents should be cultivated in foreign language education is not determined by the subjective will of the university or the higher education sector, nor is it inertially inherited, but determined by the social needs of a specific period. It is a professional talent. The market value of foreign language communication ability is reflected in its training specifications and has significant characteristics of the times. The training norms of foreign language communicative competence of various professionals must be constantly adjusted and improved with the changes of social politics, economy, culture, science and technology and other factors affecting the foreign language market value. Otherwise, the foreign language communication ability of the professional talents cultivated by colleges and universities cannot be satisfied. Social needs, graduates will have difficulties in employment, and they will not be able to perform well after graduation, which will bring economic losses to graduates, employers and society, and affect economic construction and social development. The economic value of a foreign language depends on the degree of use of the language in various tasks, occupations, and various departmental activities, and its degree of use is governed by the law of supply and demand of the language.

\section{Research on Language Economics}

The concept of Economics of Language was introduced in 1965 by the pioneer of information economics, Jacob Marschak. He believes that language is an indispensable tool in human economic activity, with the same economic attributes as other human capital, namely value, utility, cost, and benefit. Mashark has undoubtedly opened the way to reveal the economic attributes of language. His thoughts have also been supported by the theory of human capital, game theory, information 
economics and educational economics. Following Mashark, many scholars began to pay attention to the interrelationship between language and economic activity. Francois Grin, a professor of political economy at the University of Geneva in Switzerland, pioneered the concept of language economics as an independent discipline. He pointed out that language and economy interact at the micro and macro levels. Language economics belongs to the paradigm of theoretical economics, which is to introduce language as a variable into economic activities and use the concepts and tools of economics to study both. The research content mainly includes three dimensions: The influence of linguistic variables on economic variables. The impact of economic activity processes on language development processes such as linguistic dynamics. As a result, language economics has flourished as an important cross-edge discipline. Language planning refers to the systematic, rational and theoretically supported adjustment and management of the language environment by the state or social groups to increase the total welfare of the society. Language planning in the traditional sense is usually considered in terms of law, culture and education, and the economic dimension is still in the emerging field. At present, ethnic regions face the coexistence of cosmopolitan and nationality due to their special geographical relationship, and the dual opportunities and challenges of economic globalization and regional economic integration. In this context, using the theory of language economics, combining the characteristics of local economic development, and formulating a reasonable language education plan to ensure equal economic efficiency and language ecology, has a pivotal strategic significance [2].

\section{Language Economics and Language Planning in Ethnic Areas}

Ethnic areas, in the case of Yunnan Province, is located in the frontier, multi-ethnic coexistence, there are 25 ethnic minorities with a population of more than 5,000, of which 15 ethnic minorities are unique to Yunnan and 16 cross-border. Among the ethnic minorities in the province, except for the Manchu, Hui and aquarium, which currently use the national general language-Chinese, the remaining 22 ethnic minorities have their own language. At present, Yunnan Province is at the core stage of the bridgehead strategy, participating in the construction of the China-ASEAN Free Trade Area, making significant progress in the construction of the international channel, and gradually deepening its cultural, educational exchanges and economic cooperation with neighboring Southeast Asian and South Asian countries. The demand for Chinese, minority languages, foreign languages, and non-general language talents is increasing. The special language environment has brought unprecedented opportunities and challenges to language education in Yunnan Province. From the perspective of language economics, we plan language education in ethnic areas in order to reduce costs, improve efficiency, and maximize cost-benefit. At the same time, according to economic theory and method, the language is rationally set, the resource allocation is optimized, the harmonious language ecological environment is constructed on the basis of pursuing economic benefits, and the cultivation of bilingual, trilingual and even multilingual talents in minority areas is promoted. As far as the research method is concerned, the theory and method of language economics can be introduced into the language planning evaluation system, and the similar research results from abroad can be used to investigate the input cost and income and expected income of language education in ethnic areas, and to understand the general situation of language education. On this basis, through the analysis of the current situation of cost-benefit, the paper proposes strategies for language planning in ethnic areas.

For the calculation of the economic value of different languages in ethnic areas, we can learn from the method of scholar Grin. Grin divides the economic value of language into two parts: market value and non-market value. Market value is the value that can be measured by price or similar indicators. In English, for example, in other cases, the higher income earned by speaking English is the market value of English. Non-market value refers to the part of the value that is not measured by the price index. For example, because someone can speak English, he has a better understanding of English-speaking culture, has more exchanges with English native speakers, has opened up his own vision, and enhanced cross-cultural communication confidence. This is the non-market value of English. Grin continues to argue that the economic value of a particular 
language consists of private market value and private non-market value, as well as social market value and social non-market value. The total social value (SV) consists of the sum of the total private values $(\mathrm{C}+\mathrm{D})$.

According to this theory and formula, it is possible to calculate the economic value of the languages of Yunnan, Chinese, minority, and foreign languages such as English and non-universal languages such as Thai, Vietnamese, Lao, and Burmese. For an individual, it is possible to decide whether to learn or not to learn the language based on the total social value of a language. For the relevant government departments, it is possible to formulate a reasonable language plan based on this, rationally set the language, not blind, and not aggressive, not only ensuring the harmonious development of language ecology, but also striving to maximize the economic benefits [3].

In addition to the analysis of language economic value, language economics also has an important research topic - assessing the cost of language education. Using the conceptual categories and tools of economics to make a reasonable estimate of the cost of language education is an indispensable and important measure in language planning. Due to the large number of factors involved, the estimation of language education costs is very difficult. However, we can still learn from the results of previous studies and make reasonable estimates for this. Grin and Sfreddo (1998) have found through research that the cost of foreign language education in Switzerland in the secondary education stage is $\$ 1,000$ per capita per year, while the cost of foreign language education accounts for $10 \%$ of the total cost of government investment. Their research has provided guidance for the development of language planning and language policy in Switzerland. Grin (2003) pointed out that language education costs mainly include: personal input costs and government input costs.

The cost of personal input refers to the tuition and data fees that language learners invest in learning a language. Government input costs are the main source of language education costs. They include the government's investment costs in terms of curriculum, personnel, materials, and the formulation of social policies and evaluation policies. Specifically, the government's expenditure on language education, management, student size, curriculum, teacher training, teaching materials, teaching content, teaching methods, and teaching evaluation are all costs that the government invests in language education. Relevant government departments and research institutions accordingly included the investment cost of multilingual education in ethnic areas into the budget. At the same time, the market demand for various language talents was investigated, and corresponding education plans were formulated to determine the scale and input of various language education. It must be pointed out that in the process of investigation and estimation, in addition to considering the characteristics of regional economic development, factors such as the complex language environment in ethnic areas and the imbalance of regional education development should be fully considered. The language education policy of Yunnan Province is adapted to local conditions, which not only conforms to the provincial conditions, but also reflects the fairness of education, and meets market demand and social supply and demand [4].

Education in ethnic areas must serve the economic development of ethnic areas. At the same time, it is necessary to make the English learning of ethnic students obtain a certain return, and then have the corresponding educational value. From the point of view of the economic development of ethnic areas, the economy of most ethnic areas is relatively lagging behind, the degree of nationalization of the national economy is relatively low, and the disadvantages of the relatively inconvenient transportation and geographical conditions in ethnic areas, foreign investment in ethnic areas is even less. There are few economic activities in ethnic areas that need to be organized and communicated through English. This means that English education in minority areas is less urgent than other areas in English, so in the national English education plan. In addition, from the point of view of ethnic students, English, as well as Chinese and mathematics, are the main courses of national basic education. Ethnic students must pass the examination of English learning in order to obtain opportunities for further study. English education for some can enter higher education institutions. For students, such investment is worthwhile, but for other minority students who have no chance to pursue further studies, they rarely have the opportunity to use English in their return to 
farming or business, even in places where English is available. Only a relatively simple level of English is required. If, for this limited language use, English teaching is carried out from elementary school, a large number of teachers are invested, and students are put a lot of energy into it, such education obviously does not have much economic value. Therefore, whether from the economic development of ethnic areas or the English application of ethnic students, English education in ethnic areas needs to be moderately developed, and cannot be required to meet the same standards as other parts of the country [5].

With the development of ethnic areas, English education in ethnic areas can be balanced in terms of cost and return. English education cannot be limited to schools. In addition to school education, social English education should be carried out to form a more More language training institutions like New Oriental, to meet the differential English needs of minority people in business, TOEFL, exams and other aspects. The refinement and classification of folk education and school education can make the English teaching in ethnic areas be beneficially supplemented, and also enable English education in ethnic areas to obtain more economic benefits through the rational allocation of capital.

\section{Conclusion}

At present, both industry and academia have relatively scarce research on language economy and language industry in ethnic areas. This has largely hindered the economic development of ethnic areas and the creation of a harmonious language environment. As mentioned above, ethnic languages are rich in language resources but there are many practical problems. As far as Yunnan Province is concerned, due to its special geographical location, it faces the rapid development of local economic integration and the rapid demand for various language talents. At the same time, it faces the rescue and protection of ethnic minority endangered languages; dialects, minority languages Inheritance issues; the preservation of linguistic heritage, as well as the protection of property rights in various languages and their products. On this basis, it is of great significance and imminent to make overall plans for language policy and to create a harmonious language ecological environment while pursuing maximum economic benefits.

\section{References}

[1] Zhou Hong. Looking at foreign language education in China from the perspective of economic value of language [J]. Journal of Zhejiang Economic College, 2000(4): 56-59.

[2] Zhang Shanjun. College English Curriculum: Based on the Perspective of Language Economics [J]. Journal of Xinyu College, 2004(1): 84-87.

[3] Lin Yong, Song Jinfang. Comment on Language Economics [J]. Economics, 2004 (3).

[4] Mo Zaishu. Business English education from the perspective of language economics [J]. Foreign Languages, 2008 (2).

[5] Cai Jigang. ESP and the development direction of college English teaching in China [J]. Foreign Languages, 2004 (2). 